Check for updates

Cite this: RSC Adv., 2021, 11, 29690

\section{Benchmark calculations for bond dissociation energies and enthalpy of formation of chlorinated and brominated polycyclic aromatic hydrocarbons $\uparrow$}

\author{
Shenying $\mathrm{Xu}^{\mathrm{a}}{ }^{\mathrm{Q}}$ Quan-De Wang, (D) *ab Mao-Mao Sun, ${ }^{\mathrm{b}}$ Guoliang Yin ${ }^{\mathrm{a}}$ \\ and Jinhu Liang*ac
}

Thermodynamic properties, i.e., bond dissociation energies and enthalpy of formation, of chlorinated and brominated polycyclic aromatic hydrocarbons play a fundamental role in understanding their formation mechanisms and reactivity. Computational electronic structure calculations routinely used to predict thermodynamic properties of various species are limited for these compounds due to large computational cost to obtain accurate results by employing high-level wave function theory methods. In this work, a number of composite model chemistry methods (CBS-QB3, G3MP2, G3, and G4) are used to compute bond dissociation energies and enthalpies of formation of small to medium-size chlorinated and brominated polycyclic aromatic hydrocarbon compounds. The enthalpy of formation is derived via the atomization method and compared against the recommended values. Statistical analysis indicates that G4 is the best method. For comparison, three commonly used density functional theory (DFT) methods (M06-2X, $\omega B$ B97X-D and B2PLYP-D3) with various basis sets including 6-311++G(d, p), cc-pVTZ, and $\mathrm{cc}-\mathrm{pVQZ}$ in the prediction of bond dissociation energies and enthalpies of formation have been tested using the optimized geometries at the same M06-2X/6-311++G(d, p) level of theory. It is found that $\omega \mathrm{B} 97 \mathrm{X}-\mathrm{D} / 6-311++\mathrm{G}(\mathrm{d}, \mathrm{p})$ shows the best performance in computing the bond dissociation energies, while $\omega B$ B $7 X-D / c c-p V T Z$ exhibits the best prediction in enthalpy of formation of the studied reaction systems. The structural effect on the bond dissociation energies and enthalpy of formation of chlorinated and brominated polycyclic aromatic hydrocarbons are then systematically analyzed. Based on comparisons of the various methods, reliable DFT methods are recommended for future theoretical studies on large chlorinated and brominated polycyclic aromatic hydrocarbons considering both accuracy and computational cost. This work, to the authors' knowledge, is the first to systematically benchmark theoretical methods for the accurate prediction of thermodynamic properties for chlorinated and brominated polycyclic aromatic hydrocarbons.
Received 14th July 2021

Accepted 31st August 2021

DOI: $10.1039 / \mathrm{d} 1 \mathrm{ra05391d}$

rsc.li/rsc-advances controlling their emissions and human exposure to these ubiquitous pollutants. Due to the different fuel sources and combustion processes, X-PAHs can be formed in many congeners with different ring numbers, ring structures, substitution position, and number of halogenated atoms. ${ }^{1}$ These various structures significantly affect their corresponding chemical reactivity.

A better understanding of the formation and oxidation mechanisms of these compounds is of central importance to control their formation and emission during combustion process. ${ }^{1,4}$ For this purpose, it is essential to know their thermodynamic properties including the bond dissociation energies (BDEs) and enthalpy of formation $\left(\Delta_{\mathrm{f}} H\right)$. Specifically, the two parameters are not only important thermochemical properties, but also, they have Evans-Polanyi-type correlations with reaction barrier heights, which can be used to estimate the
644000, People's Republic of China. E-mail: quandewang@cumt.edu.cn

${ }^{b}$ Low Carbon Energy Institute and School of Chemical Engineering, China University of Mining and Technology, Xuzhou 221008, People's Republic of China

${ }^{c}$ School of Environment and Safety Engineering, North University of China, Taiyuan 030051, People's Republic of China.E-mail: jhliang@nuc.edu.cn

$\dagger$ Electronic supplementary information (ESI) available. See DOI: 10.1039/d1ra05391d 
activation energies of reactions when more complete experiments or theoretical calculations are not available. ${ }^{5,6}$ Traditionally, experimental determination (primarily calorimetry) is the ideal method to obtain accurate thermochemical data. However, this methodology is very laborious and timeconsuming. Further, considering the large number of species involved in detailed combustion chemical kinetic mechanism, it is effectively impossible to obtain the related thermodynamic properties of these species. ${ }^{7}$ However, with the development of accurate quantum chemistry methods and computational technologies, quantum chemistry calculations now become a major method to obtain thermodynamic properties. ${ }^{\mathbf{8 , 9}}$

The accuracy of derived thermodynamic properties from quantum chemistry depends largely on the computational methods applied and the size of the molecular system. The current implementation of coupled cluster theory in its $\operatorname{CCSD}(\mathrm{T})$ form $^{\mathbf{1 0}}$ with explicit inclusion of single and double electron excitations and perturbative inclusion of triple electron excitations together with the extrapolation of the computed energies to the basis-set limit (CBS) ${ }^{\mathbf{1 1}}$ provides computed chemical energies at an accuracy of $\sim 1 \mathrm{kcal} \mathrm{mol}^{-1}$, i.e., "chemical accuracy", thus, this method usually denoted as the "gold-standard" of quantum chemistry. However, this method is rarely achievable for large molecular systems due to the large computational cost.

Various efforts have been made to approach chemical accuracy in electronic structure methods focused on approximations to the $\operatorname{CCSD}(\mathrm{T}) / \mathrm{CBS}$ limit based on separability approximations, and the developed composite methods, ${ }^{\mathbf{1 2}}$ i.e., $\mathrm{Gn}^{\mathbf{1 3 , 1 4}}$ and CBS-QB3, ${ }^{15}$ employs a variety of methods and basis sets to improve computational accuracy. Concretely, the G4 method represents the culmination of the developed composite methods and can achieve a $2 \sigma$ accuracy of $1.1 \mathrm{kcal} \mathrm{mol}{ }^{-1}$ for a set of 114 combustion relevant heats of formation. ${ }^{13}$ However, the computational cost remains challenging for larger systems. Thus, the CBS-QB3 scheme of Peterson and coworkers ${ }^{\mathbf{1 5}}$ has found considerable use in combustion kinetics because it requires less computational resources and can be ready for applications to large systems. The G3MP2 method is selected for comparisons since it has been proven to be efficient for PAH compounds. ${ }^{16-18}$ These methods have been widely employed in theoretical studies on thermochemistry and kinetic studies of large reaction systems. ${ }^{19-21}$ Recent years, another different methodology in computational chemistry to obtain accurate chemical energies is the development of various functionals within the density functional theory (DFT) framework. ${ }^{22}$ These DFT functionals have been developed for various property predictions. ${ }^{23}$ For thermodynamic and kinetic studies in combustion community, the M06-2X, ${ }^{24} \omega \mathrm{B} 97 \mathrm{X}-\mathrm{D},{ }^{25}$ and B2PLYP-D3 (ref. 26) together with Dunning's correlation consistent basis sets (cc$\mathrm{pVnZ}, \mathrm{n}=\mathrm{D}, \mathrm{T}, \mathrm{Q} \ldots)^{11,27,28}$ have been widely used for geometry optimization and energies calculations of large systems. ${ }^{\mathbf{8} 29}$ In particular, the M06-2X functional has found widespread use in studying main group chemistry as well as in deriving thermodynamic and kinetic parameters of $\mathrm{Br}$ containing systems as flame retardants. ${ }^{30,31}$ However, accuracy of these DFT functionals and composite methods are usually system-dependent. For the reaction systems considered in this work, fewer studies have been performed to obtain accurate thermodynamic properties.

Based on the above considerations, the major objective of the present study is to determine an appropriate quantum chemical method for studying thermodynamic properties of $\mathrm{X}$ PAHs molecules and then perform a systematical theoretical study of the structural effect on the BDEs and $\Delta_{\mathrm{f}} H$ for various XPAHs. The paper is organized as follows: the computational methodology is described in Section 2, and the results and discussion, including benchmark calculations, validations of DFT, and BDEs and $\Delta_{\mathrm{f}} H$ of X-PAHs, are presented in Section 3. Section 4 summarizes the major conclusions.

\section{Computational methodology}

Four composite methods, i.e., CBS-QB3, ${ }^{15} \mathrm{G} 3,{ }^{14} \mathrm{G} 4,{ }^{13}$ and G3MP $2,{ }^{32}$ are chosen for benchmarking as part of this work. Detailed procedures of these composite methods can be found in the corresponding references. For DFT calculations, all the geometry optimization of the structures are performed using M06-2X/6-311++G(d, p) method because it achieves a suitable balance between accuracy and computational cost. Analytical harmonic frequency calculations are also carried out at this level to obtain the zero-point vibrational energies (ZPVEs) and to confirm the nature of the stationary points with no imaginary frequency. During the computation of enthalpies, the values of ZPVEs are scaled by 0.97 as recommended for the M06-2X functional. ${ }^{24}$ Single point energies are then computed using the M06-2X, wB97X-D, and B2PLYP-D3 functionals with 6$311++G(d, p)$, cc-pVTZ, and cc-pVQZ, respectively. The three DFT functionals are selected since they exhibit significant better performance for thermochemical and kinetic studies. ${ }^{\mathbf{8}, 33}$ Basis set extrapolation are not performed since there is no universal recipe for basis set extrapolation in DFT. ${ }^{34}$ All electronic structure calculations are performed using the Gaussian 09 suites of programs. ${ }^{35}$ Finally, compared with the above theoretical methods, the group additivity (GA) method provides a valuable and powerful way to quickly estimate the thermodynamic properties of molecules, which has been widely employed in modeling complex combustion reaction systems because accurate electronic structure computations are prohibitively expensive. Herein, to demonstrate the prediction accuracy of GA method for the studied X-PAHs, the obtained $\Delta_{\mathrm{f}} H_{298}$ from GA method is compared with the present theoretical results. The estimation of the $\Delta_{\mathrm{f}} H_{298}$ values using GA method are performed via the RMG software. ${ }^{36}$

The BDEs of $\mathrm{C}-\mathrm{Cl}$ and $\mathrm{C}-\mathrm{Br}$ bonds in the $\mathrm{X}-\mathrm{PAHs}$ compounds are computed using the following equation:

$$
E(\mathrm{BDE})=E_{0}(\mathrm{X}-\mathrm{PAH})-E_{0}(\mathrm{R}-\mathrm{PAH})-E_{0}(\mathrm{X})
$$

where $E_{0}(\mathrm{X}-\mathrm{PAH}), E_{0}(\mathrm{R}-\mathrm{PAH})$, and $E_{0}(\mathrm{X})$ represent the singlepoint energies of the $\mathrm{X}-\mathrm{PAH}$, the formed radical after eliminating the $\mathrm{X}$ atom in $\mathrm{X}-\mathrm{PAH}$, and the $\mathrm{Cl} / \mathrm{Br}$ atom with ZPVEs, respectively. The enthalpies of formation are computed via the 
Table 1 Structure, name, formula, together with the recommended BDEs and $\Delta_{\mathrm{f}} \mathrm{H}_{298}$ of the $\mathrm{Cl} / \mathrm{Br}$ - $\mathrm{PAH}$ compounds used for benchmark. Energy is in unit of $\mathrm{kcal} \mathrm{mol}^{-1}$

\begin{tabular}{|c|c|c|c|c|}
\hline Name & Formula & Structure & Expt. C-Cl/C-Br BDEs ${ }^{40}$ & Expt. $\Delta_{\mathrm{f}} H_{298}$ (ref. 41) \\
\hline 1-Chlorobenzene & $\mathrm{C}_{6} \mathrm{H}_{5} \mathrm{Cl}$ & & $95.5 \pm 1.5$ & 13.01 \\
\hline 2-Chlorotoluene & $\mathrm{C}_{7} \mathrm{H}_{7} \mathrm{Cl}$ & & 93.7 & - \\
\hline 1-Chloronaphthalene & $\mathrm{C}_{10} \mathrm{H}_{7} \mathrm{Cl}$ & & $96.3 \pm 2.7$ & $27.5 \pm 2.3$ \\
\hline 2-Chloronaphthalene & $\mathrm{C}_{10} \mathrm{H}_{7} \mathrm{Cl}$ & & $91.9 \pm 2.7$ & $32.8 \pm 2.4$ \\
\hline 2-Bromotoluene & $\mathrm{C}_{7} \mathrm{H}_{7} \mathrm{Br}$ & & 83.9 & - \\
\hline 1-Bromonaphthalene & $\mathrm{C}_{10} \mathrm{H}_{7} \mathrm{Br}$ & & 79.30 & $41.7 \pm 1.3$ \\
\hline 2-Bromonaphthalene & $\mathrm{C}_{10} \mathrm{H}_{7} \mathrm{Br}$ & & 81.7 & $41.97 \pm 0.55$ \\
\hline
\end{tabular}

atomization scheme, ${ }^{37}$ in which the enthalpies of formation of the gaseous component atoms are using experimentally known results as detailed in ref. 38 and 39 . To systematically evaluate the performance of different computational methods, averaged mean unsigned deviation (AMUD) and averaged mean signed deviation (AMSD) are defined as follows, i.e., for $\Delta_{\mathrm{f}} H_{298 \mathrm{~K}}$,

$$
\begin{aligned}
& \text { AMUD }=\frac{1}{n} \sum_{i=1}^{n}\left|\Delta_{\mathrm{f}} H_{298, \text { theory }}-\Delta_{\mathrm{f}} H_{298} \quad \mathrm{~K}, \exp \right| \\
& \text { AMSD }=\frac{1}{n} \sum_{i=1}^{n}\left(\Delta_{\mathrm{f}} H_{298, \text { theory }}-\Delta_{\mathrm{f}} H_{298} \mathrm{~K}, \exp \right)
\end{aligned}
$$

in which $\Delta_{\mathrm{f}} H_{298} \mathrm{~K}$,theory and $\Delta_{\mathrm{f}} H_{298} \mathrm{~K}$,exp denote the computed and experimental/recommended values, while $n$ represents the samples in the dataset. Generally, simultaneous analysis of both the AMUD and AMSD is necessary to make a conclusion on the ability of the method to provide accurate thermodynamic properties. Specifically, a computational method can be recommended if both AMUD and AMSD approach a value of zero, and of course this is the best scenario. If AMSD and the absolute value of AMUD are both large, then the computational method should not be used for the estimation of BDE and $\Delta_{\mathrm{f}} H_{298 \mathrm{~K}}$ values.

\section{Results and discussion}

The results and discussion section are organized as follows. First, we assess the ability of the examined composite and DFT methods to accurately reproduce the BDEs and enthalpies of formation for species with experimental values. Then, we proceed to discuss the BDEs and $\Delta_{\mathrm{f}} H$ of the studied reaction systems. Finally, we discuss the results obtained with group additivity method. The practical recommendations to derive accurate BDEs and $\Delta_{\mathrm{f}} H$ of the chlorinated and brominated polycyclic aromatic hydrocarbon molecules will be demonstrated.

\subsection{Benchmark results}

Table 1 lists the structures, formula, and the experimental BDE and $\Delta_{\mathrm{f}} H_{298}$ values of X-PAHs used as benchmark. AMUD and AMSD with respect to experimental values of BDEs and $\Delta_{\mathrm{f}} H_{298 \mathrm{~K}}$ obtained using four composite methods and various DFT functionals combined with $6-311++G(d, p)$, cc-pVTZ, and ccpVQZ basis sets are given in Fig. 1. For the prediction accuracy of BDEs, it can be seen that the four composite methods together with the three DFT functionals with cc-pVnZ basis sets tend to overestimate the BDE values, while the three DFT functionals with $6-311++\mathrm{G}(\mathrm{d}, \mathrm{p})$ basis set tend to slightly 

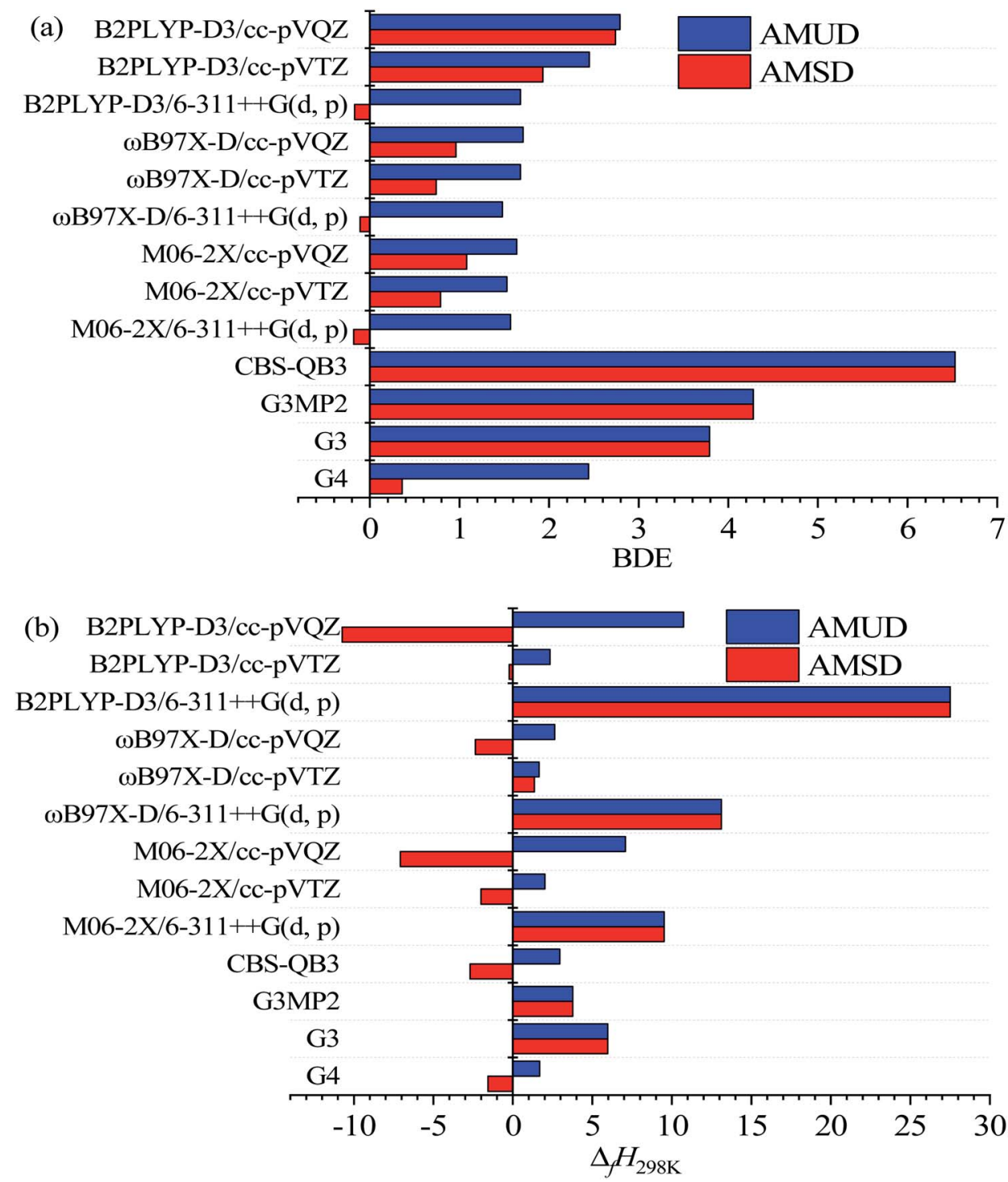

Fig. 1 Averaged mean unsigned deviation (AMUD) and averaged mean signed deviation (AMSD) with respect to experimental/recommended values of BDEs (a) and $\Delta_{f} H_{298 \mathrm{~K}}$ (b) via single-point energy results using four composite methods and three DFT functionals, i.e., M06-2X, $\omega B$ 97X$D$, and B2PLYP-D3 combined with 6-311++G(d, p), cc-pVTZ, and cc-pVQZ basis sets with the optimized geometry at M06-2X/6-311++G(d, p) level, respectively.

underestimate the BDE values according to AMUD. The selected four composite methods exhibit the following prediction accuracy as G4 > G3 > G3MP2 > CBS-QB3. The most computational expensive G4 method shows the best prediction accuracy with the AMUD and AMSD values of 2.44 and $0.36 \mathrm{kcal} \mathrm{mol}^{-1}$, respectively. The large deviations of the CBS-QB3 method in the prediction of BDEs indicate that this method is not suitable for BDE computations. For the DFT methods, it is interestingly found that the prediction accuracy of BDEs does not increase by increasing the basis set levels. The three DFT functionals with the $6-311++G(d, p)$ basis set exhibit very good performance in the computation of BDE values, probably contributed by the inclusion of diffusion function in this basis set. It can be seen that the three DFT functionals with $6-311++\mathrm{G}(\mathrm{d}, \mathrm{p})$ basis set can provide the AMSD and AMUD values within -0.2 and
$1.7 \mathrm{kcal} \mathrm{mol}^{-1}$, respectively, which is even better than the $\mathrm{G} 4$ method. Specifically, the $\omega$ B97X-D/6-311++G(d, p) method shows the best performance in prediction of BDE values.

The prediction accuracy of $\Delta_{\mathrm{f}} H_{298}$ using the selected methods exhibits very different performance compared with that of BDE results as shown in Fig. 2(b). Although the CBS-QB3 method is not suitable for the prediction of BDEs, the obtained $\Delta_{\mathrm{f}} H_{298}$ results can be comparative with the $\mathrm{G} 4$ method but with less computational cost. Specifically, the G4 method still is the best composite method for the prediction of $\Delta_{\mathrm{f}} H_{298}$, following is the CBS-QB3 method, G3MP2, and G3 methods in order. For the DFT methods, it is obvious that the small 6-311++G(d, p) basis set is not enough to accurately predict the absolute $\Delta_{\mathrm{f}} H_{298}$ values. The three DFT functionals with the moderate and widely used cc-pVTZ basis set demonstrate very good performance in 

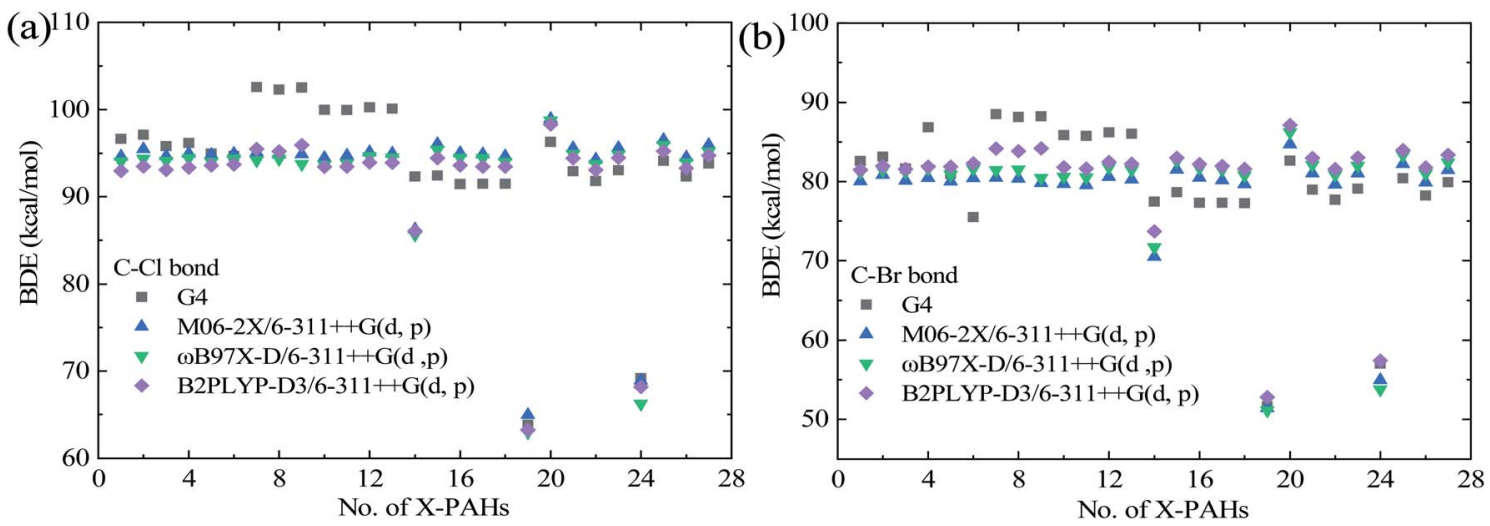

Fig. 2 Predicted $\mathrm{BDEs}$ of $\mathrm{C}-\mathrm{Cl}(\mathrm{a})$ and $\mathrm{C}-\mathrm{Br}$ (b) bond in the studied $\mathrm{X}-\mathrm{PAH}$ compounds via single-point energy computational results using various theoretical methods.

the prediction of $\Delta_{\mathrm{f}} \mathrm{H}_{298}$ values. Specifically, the B2PLYP-D3/ccpVTZ method shows the smallest AMSD, while the $\omega$ B97X-D/ccpVTZ method shows the smallest AMUD among the all the DFT methods. It is worth noting that the double-hybrid B2PLYP-D3 functional requires more computational cost arising from the MP2 component of the calculation, which limits its application to large X-PAH systems. The M06-2X/cc-pVTZ method is of comparable accuracy to the $\omega$ B97X-D/c-pVTZ and B2PLYP-D3/ cc-pVTZ methods for the studied reaction systems. Overall, the G4 method demonstrates the best performance in the prediction of both BDEs and $\Delta_{\mathrm{f}} H_{298}$, however, the computational cost is also considerably larger compared with other composite methods and DFT methods.

\subsection{BDE results}

Although the number of samples used for benchmark is less due to the experimental difficulties to obtain these data, the very large AMSD and AMUD values of some methods as shown in Fig. 1 indicate that they are not reliable for the prediction of BDEs and $\Delta_{\mathrm{f}} H_{298}$ results. However, all the methods in the prediction of BDEs and $\Delta_{\mathrm{f}} H_{298}$ results for the studied reaction systems are also carried out, and compared with the accurate methods, and details are provided in ESI. $\dagger$ For clarity, Table 2 lists the names and structures of the studied $\mathrm{Cl} / \mathrm{Br}-\mathrm{PAH}$ compounds together with the predicted BDEs and $\Delta_{\mathrm{f}} H_{298}$ results using the accurate $\mathrm{G} 4$ composite method together with the recommended DFT methods from benchmark analysis. Specifically, the BDEs results from the G4 method and $\omega$ B97X$\mathrm{D} / 6-311++\mathrm{G}(\mathrm{d}, \mathrm{p})$ method are explicitly shown, while the predicted $\Delta_{\mathrm{f}} H_{298}$ results using the G4 method and $\omega \mathrm{B} 97 \mathrm{X}-\mathrm{D} / \mathrm{cc}-$ pVTZ method are listed.

Fig. 2 displays the predicted $\mathrm{BDE}$ values of $\mathrm{C}-\mathrm{Cl}$ and $\mathrm{C}-\mathrm{Br}$ bond in the studied X-PAH molecules using various theoretical methods. From Fig. 2, the predicted BDE values using the three selected DFT methods are close to each other, and the results are also close to that from the G4 methods except for no. 7-14 XPAHs with anthracene structure. It is noted that no. 7-14 molecules are with three aromatic rings. The DFT functionals may exhibit systematic errors as the system becomes larger. ${ }^{42,43}$
Considering the accuracy of G4 method in both BDEs and $\Delta_{\mathrm{f}} H_{298 \mathrm{~K}}$ shown in Fig. 1 and the success of G4 as the culmination of a progressively more accurate set of composite schemes, ${ }^{33,38,44}$ we also compare the predicted errors using the G4 results as benchmark dataset due to the lack of accurate experimental data for large X-PAHs as shown in Table 3 . Compared with the G4 method, it can be seen that the three recommended DFT methods still shows better performance than the other three composite methods from both the AMSD and AMUD analysis. However, the AMUD error analysis results indicate that the DFT methods still exhibit large deviations compared with the G4 method, which mainly induced by the XPAH molecules with three aromatic rings. Therefore, the structural effects on both BDEs and $\Delta_{\mathrm{f}} H_{298}$ are analyzed in detail according to the G4 computational results.

From Fig. 2 and Table 2, the variation trends of BDEs for C$\mathrm{Cl}$ and $\mathrm{C}-\mathrm{Br}$ bonds for the investigated X-PAH systems are similar, indicating that the structural effect of PAHs on $\mathrm{C}-\mathrm{Cl}$ and $\mathrm{C}-\mathrm{Br}$ bonds are identical. However, the absolute $\mathrm{BDE}$ value of $\mathrm{C}-\mathrm{Cl}$ bond is larger than that of the corresponding $\mathrm{C}-\mathrm{Br}$ bond by an averaged value around $15 \mathrm{kcal} \mathrm{mol}^{-1}$, indicates that the stability of $\mathrm{C}-\mathrm{Cl}$ bond in X-PAHs is larger that of $\mathrm{C}-\mathrm{Br}$ bond, which is mainly induced by the larger atomic radius of $\mathrm{Cl}$ than $\mathrm{Br}$ atom. For both Cl-PAHs and Br-PAHs, the molecules with three aromatic rings tend to enhance the $\mathrm{C}-\mathrm{Cl}$ and $\mathrm{C}-\mathrm{Br}$ bonds due to the electron delocalization, which results higher values of BDEs. Besides this, it can be seen that the BDE values among the studied X-PAH systems changes not much except for 4Xphenanthrene (no. 14), 9-Xfluorene (no. 19), 1-Xacenaphthylene (no. 20), and 1-Xacenaphthene molecules (no. 24). The 9-chloro/bromofluorene shows the weakest $\mathrm{C}-\mathrm{Cl} / \mathrm{C}-\mathrm{Br}$ bond among the studies X-PAH molecules, following is the 1-chloro/ bromoacenaphthene. The BDE values of 1-chloroacenaphthylene and 1-bromoacenaphthylene tend to slightly larger than the other X-PAH compounds with one or two aromatic rings. Such overall reactivity trends are generally consistent with that of the $\mathrm{C}-\mathrm{Cl} / \mathrm{Br}$ bond in $\mathrm{X}-\mathrm{CH}_{3}, \mathrm{X}-\mathrm{CH}=\mathrm{CH} 2$, and X-benzene. ${ }^{40}$ However, aromatic structures still exhibit large effect on the BDE values. 
Table 2 Names and structures of the studied $\mathrm{Cl} / \mathrm{Br}-\mathrm{PAH}$ compounds together with the predicted BDEs and $\Delta_{\mathrm{f}} \mathrm{H}_{298}$ results via single-point energy computational results using different methods. Energy is in unit of $\mathrm{kcal} \mathrm{mol}^{-1}$

\begin{tabular}{|c|c|c|c|c|c|c|c|c|c|c|c|c|}
\hline \multirow[b]{3}{*}{ No. } & \multirow[b]{3}{*}{ Name $(\mathrm{X}=$ chloro/bromo $)$} & \multirow[b]{3}{*}{ Structure $(\mathrm{X}=\mathrm{Cl} / \mathrm{Br})$} & \multicolumn{4}{|l|}{ BDEs } & \multicolumn{6}{|l|}{$\Delta_{\mathrm{f}} H_{298}$} \\
\hline & & & \multicolumn{2}{|l|}{ G4 } & \multicolumn{2}{|c|}{$\begin{array}{l}\omega \mathrm{B} 97 \mathrm{X}-\mathrm{D} / 6- \\
311++\mathrm{G}(\mathrm{d}, \mathrm{p})\end{array}$} & \multicolumn{2}{|l|}{ G4 } & \multicolumn{2}{|c|}{$\begin{array}{l}\omega \mathrm{B} 97 \mathrm{X}-\mathrm{D} / \mathrm{cc}- \\
\text { pVTZ }\end{array}$} & \multicolumn{2}{|l|}{ GA } \\
\hline & & & $\mathrm{Cl}$ & $\mathrm{Br}$ & $\mathrm{Cl}$ & $\mathrm{Br}$ & $\mathrm{Cl}$ & $\mathrm{Br}$ & $\mathrm{Cl}$ & $\mathrm{Br}$ & $\mathrm{Cl}$ & $\mathrm{Br}$ \\
\hline 1 & 1-Xbenzene & & 96.65 & 82.60 & 94.04 & 81.15 & 12.81 & 24.76 & 14.58 & 25.22 & 12.7 & 22.01 \\
\hline 2 & 2-Xtoluene & & 97.12 & 83.13 & 94.37 & 81.45 & 8.59 & 15.97 & 6.68 & 17.34 & 4.71 & 14.02 \\
\hline 3 & 3-Xtoluene & & 95.81 & 81.65 & 94.12 & 81.23 & 9.54 & 21.60 & 6.92 & 17.54 & 4.71 & 14.02 \\
\hline 4 & 4-Xtoluene & & 96.15 & 86.86 & 94.44 & 81.62 & 9.74 & 16.94 & 7.11 & 17.67 & 4.71 & 14.02 \\
\hline 5 & 1-Xnaphthalene & & 94.95 & 80.96 & 93.99 & 80.87 & 27.85 & 39.75 & 32.66 & 43.46 & 27.92 & 37.23 \\
\hline 6 & 2-Xnaphthalene & & 94.67 & 75.49 & 94.38 & 81.59 & 27.88 & 39.70 & 31.90 & 42.44 & 27.92 & 37.23 \\
\hline 7 & 1-Xanthracene & & 102.55 & 88.52 & 94.18 & 81.45 & 35.25 & 65.19 & 54.09 & 64.61 & 43.14 & 52.45 \\
\hline 8 & 2-Xanthracene & & 102.25 & 88.16 & 94.33 & 81.52 & 35.20 & 65.24 & 53.63 & 64.17 & 43.14 & 52.45 \\
\hline 9 & 9-Xanthracene & & 102.49 & 88.24 & 93.74 & 80.45 & 35.67 & 65.87 & 55.26 & 66.31 & 43.14 & 52.45 \\
\hline 10 & 9-Xphenanthrene & & 99.98 & 85.87 & 93.67 & 80.62 & 30.06 & 60.15 & 48.15 & 58.90 & 40.94 & 50.25 \\
\hline 11 & 1-Xphenanthrene & & 99.95 & 85.76 & 93.82 & 80.53 & 30.27 & 60.42 & 48.10 & 59.10 & 40.94 & 50.25 \\
\hline 12 & 2-Xphenanthrene & & 100.26 & 86.20 & 94.66 & 81.81 & 29.87 & 59.90 & 47.09 & 57.68 & 40.94 & 50.25 \\
\hline 13 & 3-Xphenanthrene & & 100.11 & 86.02 & 94.49 & 81.49 & 29.79 & 59.84 & 47.06 & 57.73 & 40.94 & 50.25 \\
\hline
\end{tabular}


Table 2 (Contd.)

\begin{tabular}{|c|c|c|c|c|c|c|c|c|c|c|c|c|}
\hline \multirow[b]{3}{*}{ No. } & \multirow[b]{3}{*}{ Name $(\mathrm{X}=$ chloro/bromo $)$} & \multirow[b]{3}{*}{ Structure $(\mathrm{X}=\mathrm{Cl} / \mathrm{Br})$} & \multicolumn{4}{|l|}{ BDEs } & \multicolumn{6}{|l|}{$\Delta_{\mathrm{f}} H_{298}$} \\
\hline & & & \multicolumn{2}{|l|}{ G4 } & \multicolumn{2}{|c|}{$\begin{array}{l}\omega \mathrm{B} 97 \mathrm{X}-\mathrm{D} / 6^{-} \\
311++\mathrm{G}(\mathrm{d}, \mathrm{p})\end{array}$} & \multicolumn{2}{|l|}{ G4 } & \multicolumn{2}{|c|}{$\begin{array}{l}\omega \mathrm{B} 97 \mathrm{X}-\mathrm{D} / \mathrm{cc}- \\
\text { pVTZ }\end{array}$} & \multicolumn{2}{|l|}{ GA } \\
\hline & & & $\mathrm{Cl}$ & $\mathrm{Br}$ & $\mathrm{Cl}$ & $\mathrm{Br}$ & $\mathrm{Cl}$ & $\mathrm{Br}$ & $\mathrm{Cl}$ & $\mathrm{Br}$ & $\mathrm{Cl}$ & $\mathrm{Br}$ \\
\hline 15 & 1-Xfluorene & & 92.43 & 78.66 & 95.39 & 82.59 & 24.96 & 53.88 & 40.06 & 50.57 & 35.09 & 44.4 \\
\hline 17 & 3-Xfluorene & & 91.47 & 77.32 & 94.44 & 81.48 & 26.11 & 55.40 & 40.93 & 51.68 & 35.09 & 44.4 \\
\hline 18 & 4-Xfluorene & & 91.47 & 77.26 & 93.99 & 80.77 & 26.24 & 55.57 & 41.80 & 52.70 & 35.09 & 44.4 \\
\hline 21 & 3-Xacenaphthylene & & 92.94 & 78.97 & 94.91 & 82.08 & 43.93 & 70.95 & 60.70 & 71.27 & 44.63 & 53.94 \\
\hline 22 & 4-Xacenaphthylene & & 91.80 & 77.70 & 93.74 & 80.84 & 45.13 & 72.28 & 61.67 & 72.32 & 44.63 & 53.94 \\
\hline 23 & 5-Xacenaphthylene & & 93.02 & 79.09 & 94.83 & 81.98 & 44.51 & 71.46 & 61.41 & 71.96 & 44.63 & 53.94 \\
\hline 24 & 1-Xacenaphthene & & 69.17 & 57.01 & 66.23 & 53.74 & 13.29 & 39.74 & 33.55 & 43.87 & 20.57 & 31.48 \\
\hline
\end{tabular}




\begin{tabular}{|c|c|c|c|c|c|c|c|c|c|c|c|c|}
\hline \multirow[b]{3}{*}{ No. } & \multirow[b]{3}{*}{ Name $(\mathrm{X}=$ chloro/bromo $)$} & \multirow[b]{3}{*}{ Structure $(\mathrm{X}=\mathrm{Cl} / \mathrm{Br})$} & \multicolumn{4}{|l|}{ BDEs } & \multicolumn{6}{|l|}{$\Delta_{\mathrm{f}} H_{298}$} \\
\hline & & & \multicolumn{2}{|l|}{ G4 } & \multicolumn{2}{|c|}{$\begin{array}{l}\omega \mathrm{B} 97 \mathrm{X}-\mathrm{D} / 6- \\
311++\mathrm{G}(\mathrm{d}, \mathrm{p})\end{array}$} & \multicolumn{2}{|l|}{ G4 } & \multicolumn{2}{|c|}{$\begin{array}{l}\omega \mathrm{B} 97 \mathrm{X}-\mathrm{D} / \mathrm{cc}- \\
\mathrm{pVTZ}\end{array}$} & \multicolumn{2}{|l|}{ GA } \\
\hline & & & $\mathrm{Cl}$ & $\mathrm{Br}$ & $\mathrm{Cl}$ & $\mathrm{Br}$ & $\mathrm{Cl}$ & $\mathrm{Br}$ & $\mathrm{Cl}$ & $\mathrm{Br}$ & $\mathrm{Cl}$ & $\mathrm{Br}$ \\
\hline 26 & 4-Xacenaphthene & & 92.32 & 78.23 & 93.94 & 81.01 & 18.97 & 47.35 & 33.31 & 43.96 & 21.76 & 31.07 \\
\hline 27 & 5-Xacenaphthene & & 93.81 & 79.92 & 95.19 & 82.42 & 18.71 & 46.88 & 33.51 & 43.98 & 21.76 & 31.07 \\
\hline
\end{tabular}

Table 3 Error analysis of the predicted BDEs via single-point energy computational results using different computational methods against the G4 results

\begin{tabular}{lrr}
\hline & \multicolumn{2}{l}{ BDE } \\
\cline { 2 - 3 } Method & AMSD & AMUD \\
\hline G3 & 4.17 & 5.05 \\
G3MP2 & 5.15 & 5.92 \\
CBS-QB3 & 6.28 & 6.67 \\
M06-2X/6-311++G(d, p) & -1.21 & 3.49 \\
WB97X-D/6-311++G(d, p) & -1.13 & 3.63 \\
B2PLYP-D3/6-311++G(d, p) & -0.69 & 3.34 \\
\hline
\end{tabular}

Fig. 3 shows the optimized structures of these molecules at the M06-2X/6-311++G(d, p) level of theory. By compared the optimized structures of halogenated phenanthrene, it is found that only 4-Xphenanthrene exhibits a non-planar structure due to the interaction between $\mathrm{X}$ and adjacent $\mathrm{H}$ atoms, resulting a less stable structure compared with the other planar Xphenanthrene molecules. Thus, the corresponding $\mathrm{C}-\mathrm{Cl} / \mathrm{Br}$ bond is smaller than the other halogenated phenanthrenes. The $\mathrm{C}-\mathrm{Cl}$ and $\mathrm{C}-\mathrm{Br}$ bond in 9-chlorofluorene and 9-bromofluorene are generally smaller than that in halogenated methane and halogenated cyclohexane by approximately $20 \mathrm{kcal} \mathrm{mol}^{-1}$, revealing that the effects from the aromatic structure and adjacent $\mathrm{H}$ atom are larger to weaken the $\mathrm{C}-\mathrm{Cl}$ or $\mathrm{C}-\mathrm{Br}$ bond. The $\mathrm{C}-\mathrm{Cl}$ and $\mathrm{C}-\mathrm{Br}$ bonds in 1-chloroacenaphthene and 1-bromoacenaphthene are larger than that in 9-Xfluorene by approximately $6 \mathrm{kcal} \mathrm{mol}^{-1}$, indicating that the synergistic effect from the two aromatic rings reduces the stability of $\mathrm{C}-\mathrm{Cl}$ and $\mathrm{C}-\mathrm{Br}$ bonds in 9-Xfluorene. For 1-chloroacenaphthylene and 1- bromoacenaphthylene, the BDEs of $\mathrm{C}-\mathrm{Cl}$ and $\mathrm{C}-\mathrm{Br}$ bonds are slightly larger than the others, which can be attributed to the stabilization from the conjugative effect between the $\mathrm{C}=\mathrm{C}$ double bond and the naphthyl ring. The G4 predicted BDEs of $\mathrm{C}-\mathrm{Cl}$ and $\mathrm{C}-\mathrm{Br}$ bonds in 1-chloroacenaphthylene and 1-bromoacenaphthylene are also slightly than the corresponding $\mathrm{BDE}$ values in $\mathrm{Cl}-\mathrm{CH}=\mathrm{CH}_{2}$ and $\mathrm{Br}-\mathrm{CH}=\mathrm{CH}_{2}$ by 1.5 and $3.3 \mathrm{kcal} \mathrm{mol}^{-1}$, respectively.

\subsection{Enthalpies of formation}

Table 4 lists the error analysis of the predicted $\Delta_{\mathrm{f}} H_{298}$ using different computational methods against the $\mathrm{G} 4$ results, while Fig. 4 shows the predicted $\Delta_{\mathrm{f}} H_{298}$ values of Cl-PAH compounds (a) and Br-PAH compounds (b) using various theoretical methods. From Table 2, the AMUD values from G3 and G3MP2 methods are significantly larger, indicating that the two composite methods may be not suitable for the prediction of $\Delta_{\mathrm{f}} H_{298}$ values of the studied systems. The differences of the AMUD among the three DFT functionals with cc-pVTZ basis set and the CBS-QB3 method are small. The small value of AMSD of the CBS-QB3 methods reveals larger error cancellation effect of this method. Overall, the absolute predicted results using the methods listed in Table 2 still exhibit large deviations compared with the G4 method as explicitly shown in Fig. 4.

From Fig. 4, the $\Delta_{\mathrm{f}} H_{298}$ values of the corresponding Cl-PAH and $\mathrm{Br}-\mathrm{PAH}$ molecules show the similar variation trends as the molecular structure changes. However, the absolute $\Delta_{\mathrm{f}} H_{298}$ values of Br-PAHs are generally larger than that of the corresponding Cl-PAHs, and the deviations are strongly dependent on the molecular structures. Thus, the thermal stability of ClPAHs is generally better than the corresponding Br-PAHs. It can be seen that the halogenated toluene molecules show the 


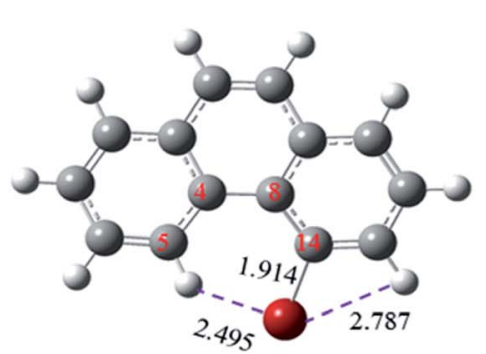

4-bromophenanthrene

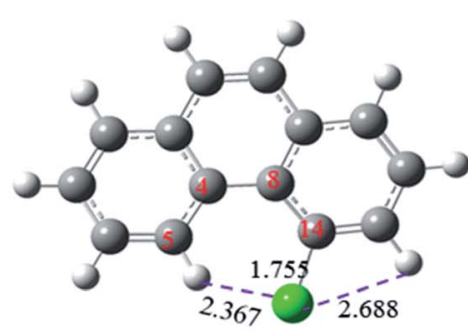

4-chlorophenanthrene

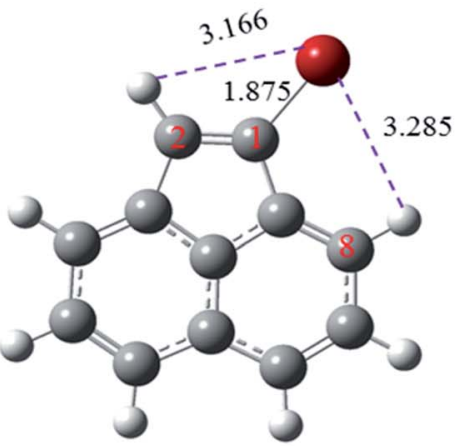

1-bromoacenaphthylene

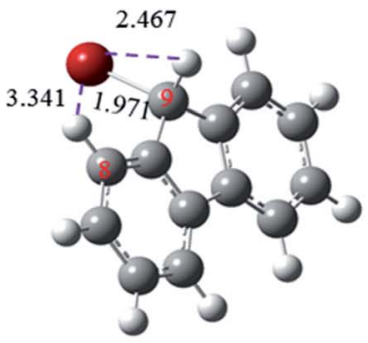

9-bromofluorene

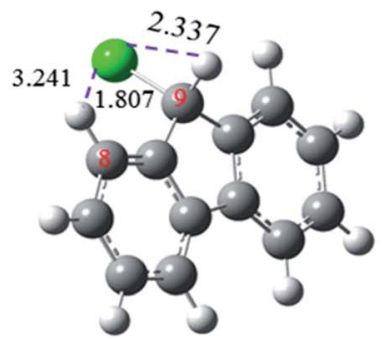

9-chlorofluorene

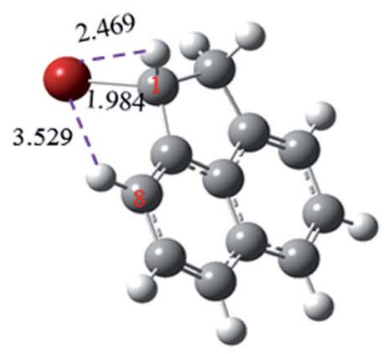

1-bromoacenaphthene

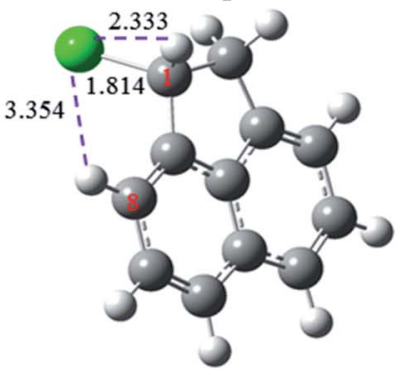

1-chloroacenaphthene

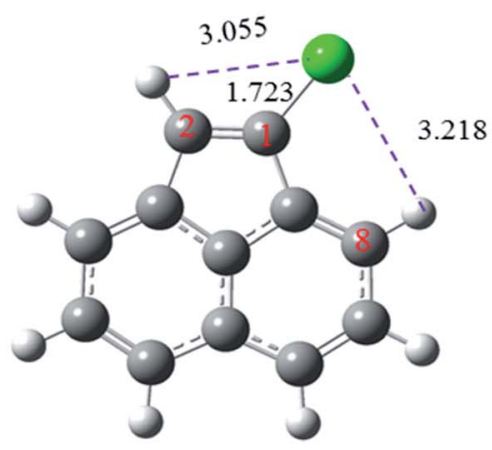

1-chloroacenaphthylene

Fig. 3 Optimized structures of 4-halogenated phenanthrene, 9-halogenated fluorene, and 1-halogenated acenaphthene at the M06-2X/6$311++G(d, p)$ level.

Table 4 Error analysis of the predicted $\Delta_{\mathrm{f}} \mathrm{H}_{298}$ via single-point energy computational results using different computational methods against the G4 results

\begin{tabular}{lrr}
\hline & $\Delta_{\mathrm{f}} H_{298}$ & \\
\cline { 2 - 3 } Method & AMSD & AMUD \\
\hline G3 & 11.92 & 11.92 \\
G3MP2 & 4.59 & 17.94 \\
CBS-QB3 & 0.03 & 7.68 \\
M06-2X/cc-pVTZ & 2.47 & 6.88 \\
$\omega$ B97X-D/cc-pVTZ & 6.37 & 7.99 \\
B2PLYP-D3/cc-pVTZ & 4.57 & 8.51 \\
GA & -2.95 & 8.11 \\
\hline
\end{tabular}

smallest $\Delta_{\mathrm{f}} H_{298}$ values, while the halogenated acenaphthylene molecules are with the largest $\Delta_{\mathrm{f}} H_{298}$ values. The substituted positions of $\mathrm{Cl}$ and $\mathrm{Br}$ atoms on the PAHs exhibit small effect on the $\Delta_{\mathrm{f}} H_{298}$ except for halogenated acenaphthene molecules due to the substitution at the $\mathrm{C}-\mathrm{C}$ single bond position and 4Xphenanthrene induced by the specific substituted positions. Further, it can be seen that the $\Delta_{\mathrm{f}} H_{298}$ values of halogenated acenaphthylene molecules are larger than that of the halogenated acenaphthene molecules. However, it is hard to found a general relationship between $\Delta_{\mathrm{f}} H_{298}$ and the number of aromatic rings for the studied X-PAHs.

The derived enthalpies of the studied X-PAHs and error analysis results from GA method are also shown in Tables 2 and 4. The AMSD and AMUD values for GA method compared with the G4 method are -2.95 and $8.11 \mathrm{kcal} \mathrm{mol}^{-1}$, respectively. This indicates that the overall performance of GA method can be comparable with the DFT methods. However, obvious limitation of the GA method still exists. A major drawback is that the GA method cannot accurately reveal some of the position effect on the $\Delta_{\mathrm{f}} H_{298}$ values, i.e., the predicted $\Delta_{\mathrm{f}} H_{298}$ of the halogenated naphthalene, and halogenated phenanthrene molecules 

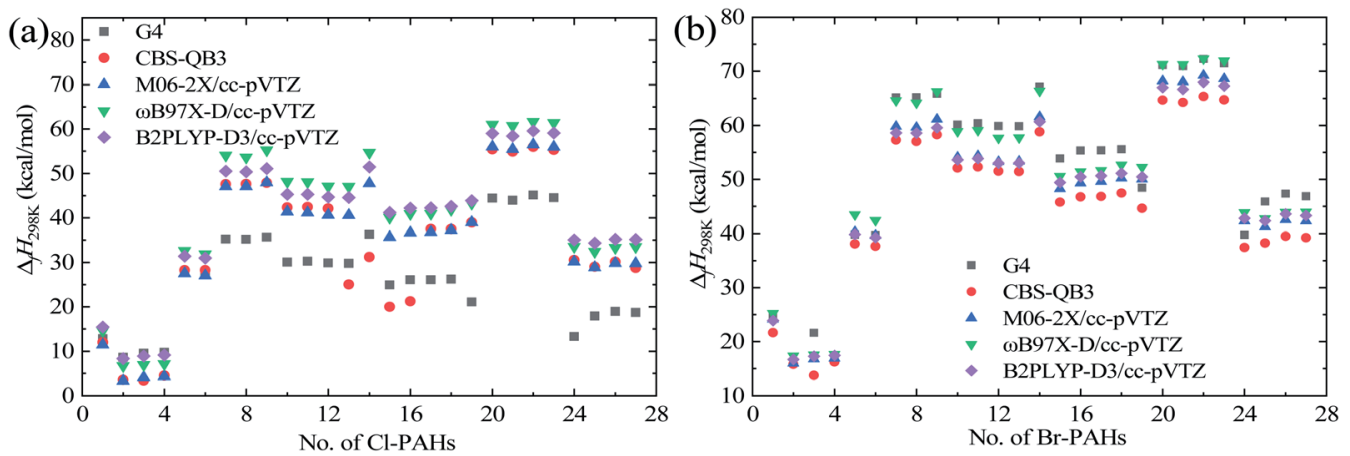

Fig. 4 Predicted $\Delta_{\mathrm{f}} \mathrm{H}_{298}$ values of $\mathrm{Cl}$-PAH compounds (a) and $\mathrm{Br}$-PAH compounds (b) via single-point energy computational results using various theoretical methods.

are identical for different substituted positions. Thus, although the GA method provide an efficient way to quickly estimate the thermodynamic properties, it is not recommended to study the substituted position effect on the X-PAHs. Nonetheless, the number of aromatic rings and structural effect on the $\Delta_{\mathrm{f}} H_{298}$ of the studied X-PAHs can be well captures via the GA method, and the obtained absolute results can also be well predicted.

Finally, the computational cost of the employed various theoretical methods is compared as shown in Table 5 for the medium sized molecules, i.e., 1-chloronaphthalene and 1-bromonaphthalene. Considering the smaller difference between 6$311++\mathrm{G}(\mathrm{d}, \mathrm{p})$ and cc-pVTZ basis sets in DFT calculations, Table 5 only explicitly shows the relative computational cost from ccpVTZ basis set in combination with different functionals. The cc-pVQZ basis set does not significantly improves the prediction accuracy for both BDEs and $\Delta_{\mathrm{f}} H_{298}$, thus, it also not considered due to the large computational cost compared with the other two basis sets. Assuming the computational time cost for calculations from M06-2X/cc-pVTZ method is 1 by using 20-core Intel Xeon Silver CPU, Table 5 explicitly shows the relative computational cost of typical methods. It is worth noting that the B2PLYP-D3 functional exhibits large computational cost for single-point energy calculations neglecting the optimization process compared with the other functionals due to the inclusion of MP2 component of the calculation, which is not

Table 5 Computational cost analysis of the theoretical methods used in present work. It is worth noting that the DFT calculations include the geometry and frequency computational cost at M06-2X/6-311++G(d, p) level

\begin{tabular}{lll}
\hline & \multicolumn{2}{c}{ Relative computational time } \\
\cline { 2 - 3 } Method & 1-Chloronaphthalene & 1-Bromonaphthalene \\
\hline G4 & $\sim 14$ & $\sim 18$ \\
G3 & $\sim 8.4$ & $\sim 11$ \\
G3MP2 & $\sim 1.8$ & $\sim 3.0$ \\
CBS-QB3 & $\sim 3.4$ & $\sim 5.5$ \\
M06-2X/cc-pVTZ & 1 & 1 \\
WB97X-D/cc-pVTZ & $\sim 1.05$ & $\sim 1.05$ \\
B2PLYP-D3/cc-pVTZ & $\sim 1.8$ & $\sim 1.8$
\end{tabular}

recommended for large similar systems. Although the G3MP2 method shows smaller computational cost compared with the other composite methods, it is not recommended due to large deviations. Further, the relative computational cost of composite methods increases as molecular size increases. Therefore, the composite CBS-QB3 method and $\omega$ B97X-D functional are recommended for large reaction systems.

\section{Conclusions}

In this work, we perform theoretical studies on the BDEs of C-Cl and $\mathrm{C}-\mathrm{Br}$ bonds of $27 \mathrm{Cl}$ - and $\mathrm{Br}-\mathrm{PAHs}$ together with their corresponding $\Delta_{\mathrm{f}} H_{298}$. Four composite model chemistry methods including CBS-QB3, G3MP2, G3, and G4 together with three widely used DFT functionals with various basis sets in the prediction of the BDEs and $\Delta_{\mathrm{f}} H_{298}$ are firstly compared with the experimental results, and statistical analysis indicates that $\mathrm{G} 4$ is the only method that can approach the "chemical accuracy" (approximately 1-2 $\mathrm{kcal} \mathrm{mol}^{-1}$ ) for both BDEs and $\Delta_{\mathrm{f}} \mathrm{H}_{298}$. Due to the lack of accurate data for large X-PAHs, the G4 method is further used as the benchmark for the other methods. It is found that the predicted BDEs of $\mathrm{C}-\mathrm{Cl}$ and $\mathrm{C}-\mathrm{Br}$ bonds in $\mathrm{X}$ PAHs using DFT method are dependent on basis set. Specifically, the three M06-2X, $\omega$ B97X-D, and B2PLYP-D3 DFT functionals with $6-311++\mathrm{G}(\mathrm{d}, \mathrm{p})$ exhibits similar performance, and the $\omega \mathrm{B} 97 \mathrm{X}-\mathrm{D} / 6-311++\mathrm{G}(\mathrm{d}, \mathrm{p})$ method is slightly better than the other two methods. For $\Delta_{\mathrm{f}} H_{298}$, the CBS-QB3 method and the three DFT functionals with cc-pVTZ basis set exhibit similar performance, but the deviations remain larger compared with the G4 method, especially for Cl-PAHs. The GA method can provide comparable results with the CBS-QB3 and DFT methods, however, it cannot reveal the position effect of typical halogenated PAHs. Thus, the G4 method is still recommended to obtain accurate $\Delta_{\mathrm{f}} H_{298}$ values. However, the GA method provides a quick and efficient way to obtain reliable $\Delta_{\mathrm{f}} H_{298}$ results for large X-PAHs when position effect is not the research focus. Using the G4 results, the structural effect and substituted position effect on the BDEs of $\mathrm{C}-\mathrm{Cl}$ and $\mathrm{C}-\mathrm{Br}$ bonds in the studied X-PAHs and the $\Delta_{\mathrm{f}} H_{298}$ are systematically analyzed. It is found that structural and position effects on the BDEs and $\Delta_{\mathrm{f}} H_{298}$ exhibit very similar variation trends. The thermal 
stability of Cl-PAHs is generally better than the corresponding Br-PAHs from the computed $\Delta_{\mathrm{f}} H_{298}$, which results in the $\mathrm{C}-\mathrm{Br}$ bond is smaller than the corresponding $\mathrm{C}-\mathrm{Cl}$ bond in X-PAHs. Further, no linear relationship is found between the number of aromatic rings and the BDEs or $\Delta_{\mathrm{f}} H_{298}$ values. The present work provides valuable guidance for the future estimation of thermodynamic properties of large X-PAH molecules.

\section{Author contributions}

Shenying Xu: investigation, data curation, original draft preparation. Quan-De Wang: supervision, project administration, conceptualization, writing-reviewing and editing. Mao-Mao Sun: methodology, formal analysis, data curation. Guoliang Yin: conceptualization, data curation, formal analysis. Jinhu Liang: data curation, visualization, writing-reviewing and editing.

\section{Conflicts of interest}

There are no conflicts to declare.

\section{Acknowledgements}

We thank National Supercomputing Center in Shenzhen for providing the computational resources and Gaussian 09 suite of programs (Revision D.01). S. Xu acknowledges financial support from Sailing Project of Yibin University (XJ2020007702). Q.-D. Wang and J. Liang acknowledge financial support from the opening funds of Functional Materials and Resource Utilization Lab of Yibin University.

\section{References}

1 R. Jin, M. Zheng, G. Lammel, B. A. M. Bandowe and G. Liu, Prog. Energy Combust. Sci., 2020, 76, 100803.

2 J. L. Sun, H. Zeng and H. G. Ni, Chemosphere, 2013, 90, 17511759.

3 C. Ding, H. G. Ni and H. Zeng, Environ. Pollut., 2012, 168, 8086.

4 Q. Z. Liu, X. Xu, L. Wang and D. H. Wang, Chem. Eng. J., 2020, 400, 125901.

5 M. G. Evans and M. Polanyi, Trans. Faraday Soc., 1936, 32, 1333-1360.

6 J. L. Bao, R. Meana-Paneda and D. G. Truhlar, Chem. Sci., 2015, 6, 5866-5881.

7 H. J. Curran, Proc. Combust. Inst., 2019, 37, 57-81.

8 S. J. Klippenstein, Proc. Combust. Inst., 2017, 36, 77-111.

9 M. Keceli, S. N. Elliott, Y. P. Li, M. S. Johnson, C. Cavallotti, Y. Georgievskii, W. H. Green, M. Pelucchi, J. M. Wozniak, A. W. Jasper and S. J. Klippenstein, Proc. Combust. Inst., 2019, 37, 363-371.

10 J. D. Watts, J. Gauss and R. J. Bartlett, J. Chem. Phys., 1993, 98, 8718-8733.

11 K. A. Peterson, D. E. Woon and T. H. Dunning Jr, J. Chem. Phys., 1994, 100, 7410-7415.
12 K. Raghavachari and A. Saha, Chem. Rev., 2015, 115, 56435677.

13 L. A. Curtiss, P. C. Redfern and K. Raghavachari, J. Chem. Phys., 2007, 126, 084108.

14 L. A. Curtiss, P. C. Redfern, V. Rassolov, G. Kedziora and J. A. Pople, J. Chem. Phys., 2001, 114, 9287-9295.

15 J. A. Montgomery, M. J. Frisch, J. W. Ochterski and G. A. Petersson, J. Chem. Phys., 1999, 110, 2822-2827.

16 C. C. Chen, J. W. Bozzelli and J. T. Farrell, J. Phys. Chem. A, 2004, 108, 4632-4652.

17 G. Blanquart and H. Pitsch, J. Phys. Chem. A, 2007, 111, 65106520.

18 T. C. Allison and D. R. Burgess, J. Phys. Chem. A, 2015, 119, 11329-11365.

19 Q.-D. Wang and Z.-W. Liu, J. Phys. Chem. A, 2018, 122, 52025210.

20 Q.-D. Wang, J. Phys. Org. Chem., 2017, 30, e3668.

21 L. Lai and W. H. Green, J. Phys. Chem. A, 2019, 123, 31763184.

22 N. Mardirossian and M. Head-Gordon, Mol. Phys., 2017, 115, 2315-2372.

23 P. Verma and D. G. Truhlar, Trends Chem., 2020, 2, 302-318. 24 Y. Zhao and D. G. Truhlar, Theor. Chem. Acc., 2008, 120, 215241.

25 J. D. Chai and M. Head-Gordon, Phys. Chem. Chem. Phys., 2008, 10, 6615-6620.

26 S. Grimme, J. Antony, S. Ehrlich and H. Krieg, J. Chem. Phys., 2010, 132, 154104.

27 T. H. Dunning Jr, J. Chem. Phys., 1989, 90, 1007-1023.

28 D. E. Woon and T. H. Dunning, J. Chem. Phys., 1993, 98, 1358-1371.

29 S. J. Klippenstein, L. B. Harding and B. Ruscic, J. Phys. Chem. A, 2017, 121, 6580-6602.

30 D. Maftei, D.-L. Isac, M. Dumitraș, Ș. Bucur and A.-C. Dîrţu, Struct. Chem., 2018, 29, 921-927.

31 M. Altarawneh, A. Saeed, M. Al-Harahsheh and B. Z. Dlugogorski, Prog. Energy Combust. Sci., 2019, 70, 212-259.

32 L. A. Curtiss, P. C. Redfern, K. Raghavachari, V. Rassolov and J. A. Pople, J. Chem. Phys., 1999, 110, 4703-4709.

33 S. J. Klippenstein and C. Cavallotti, in Mathematical modelling of gas-phase complex reaction systems: pyrolysis and combustion, 2019, pp. 115-167, DOI: 10.1016/b978-0444-64087-1.00002-4.

34 P. Kraus, J. Chem. Theory Comput., 2020, 16, 5712-5722.

35 M. J. Frisch, G. W. Trucks, H. B. Schlegel, G. E. Scuseria, M. A. Robb, J. R. Cheeseman, J. A. Montgomery, T. Vreven, K. N. Kudin, J. C. Burant, J. M. Millam, S. S. Iyengar, J. Tomasi, V. Barone, B. Mennucci, M. Cossi, G. Scalmani, N. Rega, G. A. Petersson, H. Nakatsuji, M. Hada, M. Ehara, K. Toyota, R. Fukuda, J. Hasegawa, M. Ishida, T. Nakajima, Y. Honda, O. Kitao, H. Nakai, M. Klene, X. Li, J. E. Knox, H. P. Hratchian, J. B. Cross, V. Bakken, C. Adamo, J. Jaramillo, R. Gomperts, R. E. Stratmann, O. Yazyev, A. J. Austin, R. Cammi, C. Pomelli, J. W. Ochterski, P. Y. Ayala, K. Morokuma, G. A. Voth, P. Salvador, J. J. Dannenberg, V. G. Zakrzewski, S. Dapprich, 
A. D. Daniels, M. C. Strain, O. Farkas, D. K. Malick, A. D. Rabuck, K. Raghavachari, J. B. Foresman, J. V. Ortiz, Q. Cui, A. G. Baboul, S. Clifford, J. Cioslowski, B. B. Stefanov, G. Liu, A. Liashenko, P. Piskorz, I. Komaromi, R. L. Martin, D. J. Fox, T. Keith, A. Laham, C. Y. Peng, A. Nanayakkara, M. Challacombe, P. M. W. Gill, B. Johnson, W. Chen, M. W. Wong, C. Gonzalez and J. A. Pople, Gaussian 09, Revision D.01, Gaussian, Inc., Wallingford CT, 2013.

36 M. Liu, A. Grinberg Dana, M. S. Johnson, M. J. Goldman, A. Jocher, A. M. Payne, C. A. Grambow, K. Han, N. W. Yee, E. J. Mazeau, K. Blondal, R. H. West, C. F. Goldsmith and W. H. Green, J. Chem. Inf. Model., 2021, 61, 2686-2696.

37 L. A. Curtiss, K. Raghavachari, P. C. Redfern and J. A. Pople, J. Chem. Phys., 1997, 106, 1063-1079.
38 B. Ruscic and D. H. Bross, in Mathematical Modelling of GasPhase Complex Reaction Systems: Pyrolysis and Combustion, 2019, pp. 3-114, DOI: 10.1016/b978-0-444-64087-1.00001-2.

39 B. Ruscic, J. Phys. Chem. A, 2015, 119, 7810-7837.

40 Y.-R. Luo, Handbook of bond dissociation energies in organic compounds, CRC press, 2002.

41 P. J. Linstrom and W. G. Mallard, NIST Chemistry WebBook, NIST Standard Reference Database Number 69, retrieved June 6, 2021.

42 R. Sivaramakrishnan, R. S. Tranter and K. Brezinsky, J. Phys. Chem. A, 2005, 109, 1621-1628.

43 P. C. Redfern, P. Zapol, L. A. Curtiss and K. Raghavachari, J. Phys. Chem. A, 2000, 104, 5850-5854.

44 J. M. Simmie and K. P. Somers, J. Phys. Chem. A, 2015, 119, 7235-7246. 